\title{
Simulation of Near Source Two-Dimensional Wave Field and its Application to the Study of Ground Motion Characteristics of the 1999 Chi-Chi, Taiwan Earthquake
}

\author{
Yi-Ling Huang ${ }^{1, *}$, Bor-Shouh Huang ${ }^{2}$, Kuo-Liang Wen ${ }^{1,3}$ \\ (Manuscript received 16 Septemper 2003, in final form 5 November 2003)
}

\begin{abstract}
The characteristics of near source two-dimensional strong groundmotion resulting from complex fault rupture processes and velocity structures have been examined based on two-dimensional wave field modeling. To construct the two-dimensional surface seismic wave field, the synthetic seismogram of each grid space was simulated by theoretical Green's functions. Numerical experiments were constructed by testing different source parameters and velocity structures. The analysis undertaken in this study can be considered as a two-dimensional seismic waveform analysis and offered as a wider view for studying the wave propagation from a large earthquake. Results of this study provide significant information about the temporal and spatial wave field snapshots on the near source area. It is found that the wave fields are strongly affected by the changes of fault geometries, rupture velocities and near fault seismic velocity structures. In this study, the newly developed wave field simulation procedure is applied to analyze the near source ground motion characteristics of the 1999 ChiChi, Taiwan earthquake. Summing up the modeling results and comparing with the observed near source wave field of the Chi-Chi earthquake, we find that the Chelungpu fault has lower seismic velocity in the footwall than in the hanging wall, and seismic velocities of the footwall side, at least on its surface, are lower than its apparent rupture velocities.
\end{abstract}

(Key words: Near source two-dimensional strong ground-motion, Temporal and spatial distribution snapshots of ground-motion, The Chi-Chi earthquake)

\footnotetext{
${ }^{1}$ Institute of Geophysics, National Central University, Chung-Li, Taiwan, ROC

2 Institute of Earth Sciences, Academia Sinica, Taipei, Taiwan, ROC

3 Institute of Applied Geology, National Central University, Chung-Li, Taiwan, ROC

* Corresponding author address: Prof. Yi-Ling Huang, Institute of Geophysics, National Central University, Chung-Li, Taiwan, ROC; E-mail: ylhuang@earth.sinica.edu.tw
} 


\section{INTRODUCTION}

Near source ground-motion is the most significant factor bringing about large earthquake disasters. Detailed analysis of the near source ground-motion characteristics of an earthquake provides precious information about its source and seismic velocity structures. The deployment of strong motion instruments in many seismically active areas has provided an invaluable collection of near source data on the motion of the ground during earthquakes. However, since these data yield absolute ground motion at discrete locations and usually the spacing between recording sites is much larger than the wavelengths of the analyzed seismic waves, the spatial information from nearby seismic records usually are not used. Otherwise, analyzed results using different constraints can be different within the same data set. For example, waveform modeling for source rupture processes (Hartzell and Heaton 1983; Takeo 1987; Beroza and Spudich 1988) and lateral variations in the earth crust (Wen and Helmberger 1997) have been considered so as to minimize errors in the observed seismograms. However, due to spatial aliasing of the data, uncertainties with regard to waveform fitting were difficult to evaluate from seismograms with station spacing greater than the signal wavelengths of interest.

A major earthquake $\left(\mathrm{M}_{\mathrm{w}}=7.6\right)$ occurred near the town of Chi-Chi in Nantou Country in central Taiwan at 1:47 a.m. (local time), September 21, 1999 (UTC was 17:47, 20 September 1999). This was the largest inland earthquake in the past 100 years in Taiwan. This disastrous earthquake was well recorded by more than 400 free field digital accelerometers operated by the Central Weather Bureau (CWB) which has monitored earthquake activities in Taiwan since 1990 (Shin 1993). The data set represents the most complete strong-motion records in the world for studying the disastrous earthquake's source rupture processes and ground motions. Many important discoveries about this centurial earthquake have been studied and reported. The location and source type have been examined by using seismic data (Shin et al. 2000; Wang et al. 2000), waveform inversions (Kikuchi et al. 2000; Lee and Ma 2000; Ma et al. 2000), and forward simulations (Dalguer et al. 2001; Huang 2000; Huang et al. 2000; Oglesby and Day 2001). Although, it is realized that the seismic data from the 1999 Chi-Chi, Taiwan earthquake provided an unique opportunity to study the earthquake source properties based on the spatial information between seismic records, nonetheless, till now, only a few reports have discussed the source properties in using the this information.

In this study, a modeling procedure is developed to construct a two-dimensional (2-D) wave field and to analyze the characteristics of near source strong ground motion resulting from fault rupture processes and velocity structures. The temporal and spatial strong-motion snapshots around the near fault region were established and analyzed to inquire how the fault dip angle, velocity structure, and rupture.velocity influenced the ground-motion energy distribution. Results of this study can be considered as a two-dimension seismic record analysis and be offered as a wider view for studying the ground-motion as results of a large earthquake. Employing these modeling results, the near source ground motion characteristics of the ChiChi earthquake were examined based on its temporal and spatial variations. They indicate that the Chelungpu fault had lower seismic velocity in the footwall than in the hanging wall, and seismic velocities of the footwall side, at least on its surface, are lower than its apparent rupture velocities. 


\section{METHOD AND MODEL CONSTRUCTION}

To construct the 2-D wave fields, the ground motion should be extracted from the 2-D grid points of the study area. To consider the temporal variation of the wave field, the seismic seismogram on each grid was required. In this study, the synthetic seismogram as displacement record on each surface grid point was simulated by the summarized dislocation point source rupture on the grid points of the fault plan. Herein, the point dislocation was constructed by a set of full waveform Green's functions (Johnson 1974). Finally, to simulate a finite fault source rupture, the seismogram on each surface grid point was obtained by summarizing the point source seismogram over each grid point of fault plan. Herein, to convert synthetic seismogram of an individual point to a 2-D wave field as a snapshot, a Green's function database was constructed. In detail, the procedure in obtaining a seismogram involves following the flow chart as shown in Fig. 1. To learn the characteristics of the 2-D wave field from a

The simple flow chart to compute the 2-D synthetic wave field

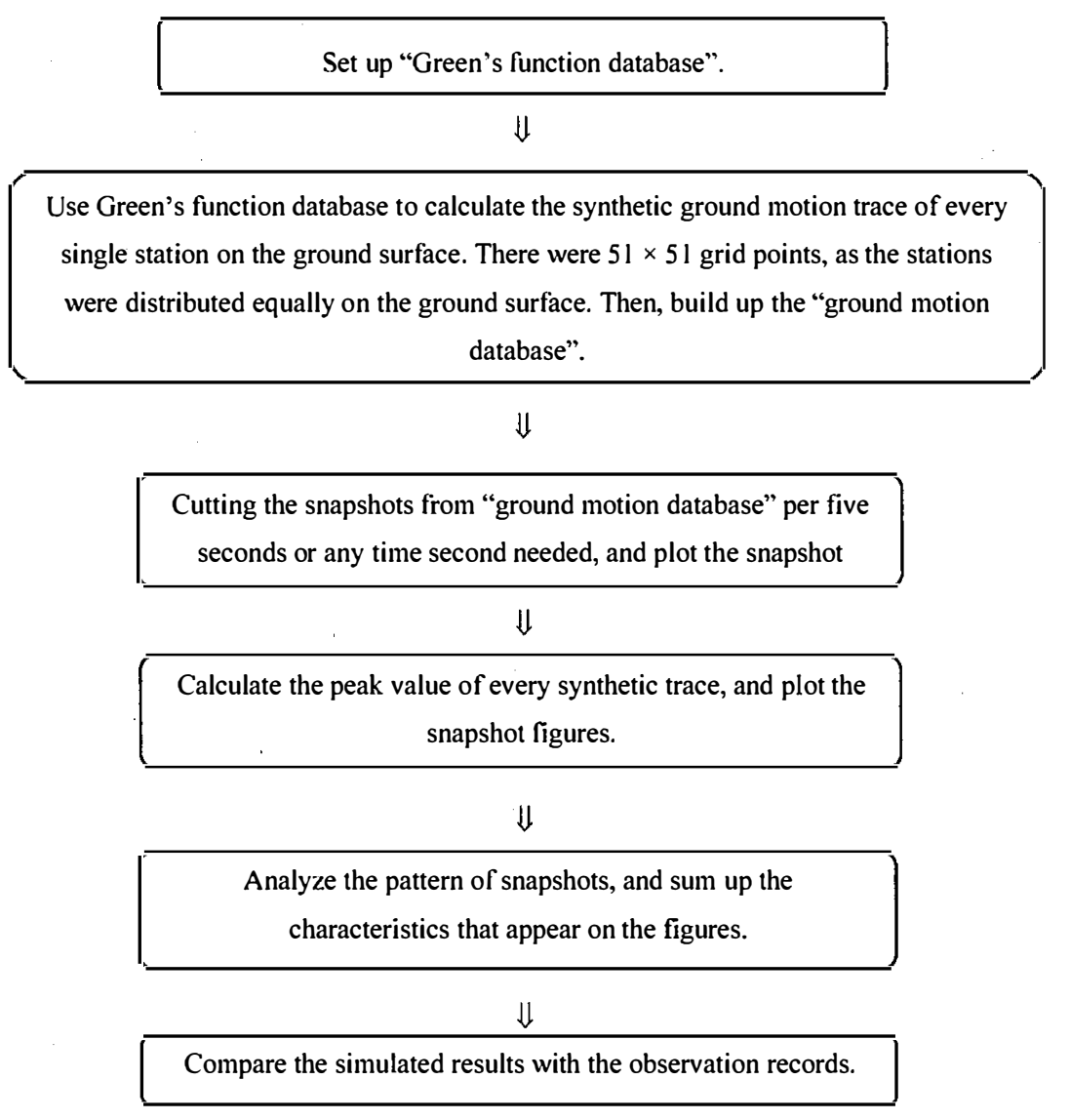

Fig. 1. Simple flow chart to represent the computation procedure generating the synthetic 2-D wave fields, etc. 
complex source rupture, numerical models, including several different dip angles and velocity structures are examined. Finally, the spatial distribution snapshots of ground-motion at each selected time were obtained for future studies.

According to numerical simulation, it is found that, in homogeneous medium, the main features of near source ground motion were caused by its source rupture properties. In order to model the influences from the source rupture, we designed several source models to simulate the ground motion, and tried to summarize the characteristics from the simulated results. We also found that the dip angle plays the major role in influencing the near source ground motion characteristics. To demons ate the effect of source dip angle, we first set the source models as a line source and a plane source with a different dip angle: $15^{\circ}, 30^{\circ}, 45^{\circ}, 60^{\circ}$, and $90^{\circ}$. All source models had the same strike and slip angles that were $0^{\circ}$ and $90^{\circ}$, and the rupture direction was from south to north with uniform rupture velocity that was 0.8 times the $\mathrm{S}$ wave velocity. In the case of line source, the fault dimension was assigned as $90 \mathrm{~km}$ in length, and in the case of the plane source, it was defined as $90 \mathrm{~km}$ and $25 \mathrm{~km}$ in length and width, respectively. In both cases, a seismic velocity model with P-wave and S-wave velocity of $6.15 \mathrm{~km} \mathrm{~s}^{-1}$ and $3.55 \mathrm{~km} \mathrm{~s}^{-1}$ were assumed, respectively.

In cases of a non-homogeneous medium, we examine the difference of velocity structure on the hanging wall and on the footwall which may have the remarkable effect in influencing the ground motion. We analyzed the ground motion effect induced by different wave velocities on the hanging wall and on the footwall side.

The rupture velocity of a finite fault was considered as another major factor to influencing the ground motion characteristics. In the second step of this study, we try to test the nonuniform rupture velocity case and sum up the influences from rupture velocity. Herein, the rupture velocities are examined in different cases, which are from 0.8 times the $S$ wave velocity to 0.6 times the $S$ wave velocity, and the rupture direction is considered to propagate from the southern end of fault to its northern end.

\section{ANALYZED RESULTS}

After the systematic modeling for cases of different source and velocity models, the database of 2-D wave fields was constructed. Those simulated time-dependent 2-D ground motions may provide critical constraints to assist with waveform modeling in the study of source rupture processes and seismic amplifications in different soil conditions. Herein, results of this study will focus to the near source ground motion characteristics induced by different source parameters. Sensitivity of some selected source and velocity parameters are closely examined in the following section.

\subsection{Influences of Fault Plane Dip Angle}

Dip angle of a fault plane is an important factor influencing the ground-motion directivity that was displayed on the ground-motion snapshots. Figure 2 shows the simulated groundmotion snapshots in different dip angles of an underground rupture case. The simulated ground- 

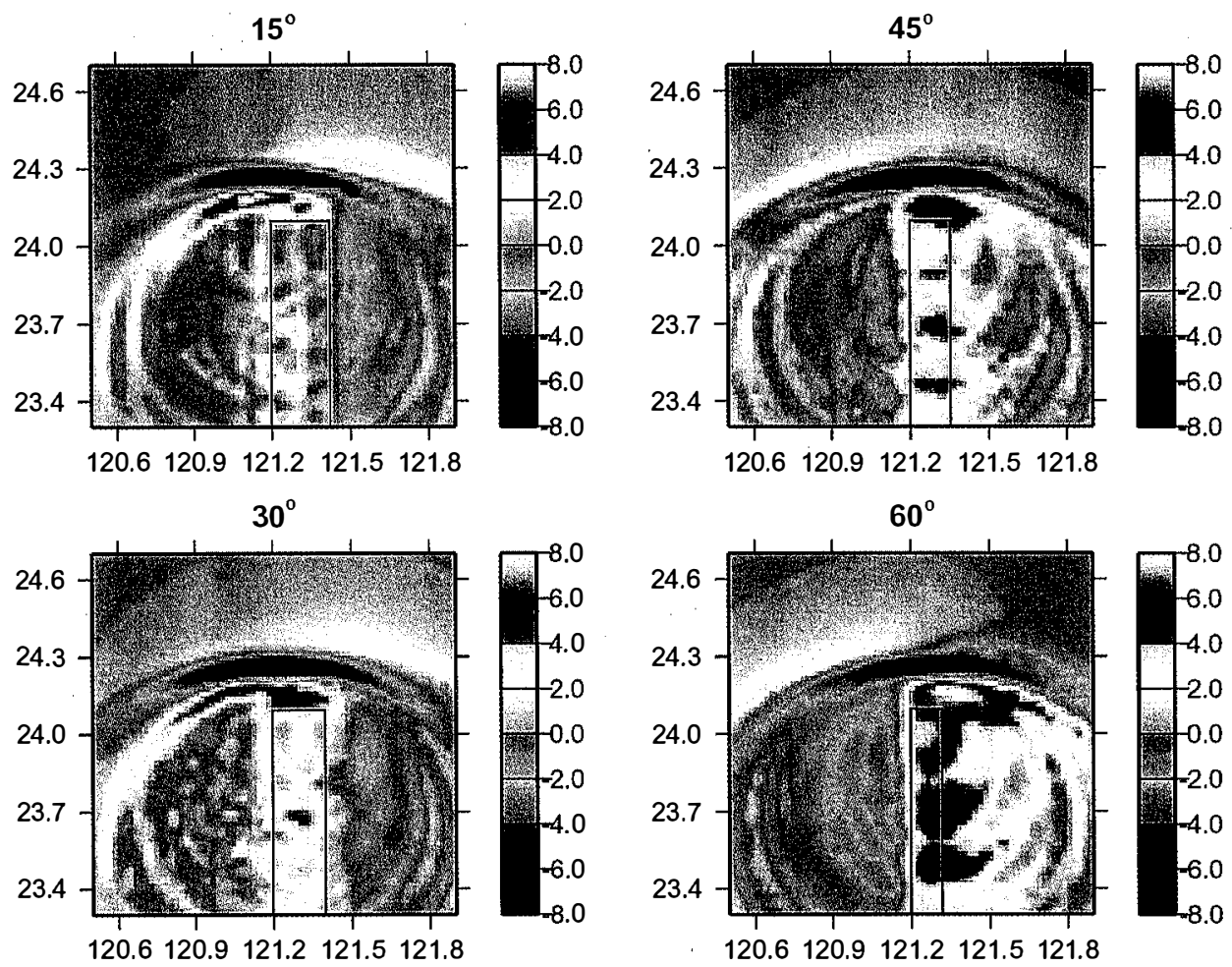

Fig. 2. Simulated ground motion snapshots. These snapshots depict the surface motion $35 \mathrm{sec}$ after the initiation of the rupture process. The red rectangle shows the fault outline projected on the ground surface. The colors and numbers on the scale bar indicate the ground motion of the wave field. The positive numbers indicate the upward ground motion, and the negative numbers indicate the downward ground motion.

motion snapshots demonstrated that the upper boundary of the fault plane could be identified more clearly in the high dip angle case than in the lower dip angle case. Figure 3 presents the snapshots of the peak value distribution of the simulated ground-motion with different dip angles. The pattern of peak value snapshots displayed the directivity of source rupture direction more clearly with high dip angle then with lower dip angle. Examining the difference in ground-motion peak value between the positions above the rupture start and the rupture end in different dip angles, we found that the dip angle of rupture plane could be a remarkable factor influencing the ground-motion and high dip angle induced high amplitude difference.

\subsection{Influences of Velocity Structure}

In testing for the influence of discrepant velocity structures, we assumed there was a discrepancy of wave velocity in the hanging wall and in the footwall. Figure 4a shows the 

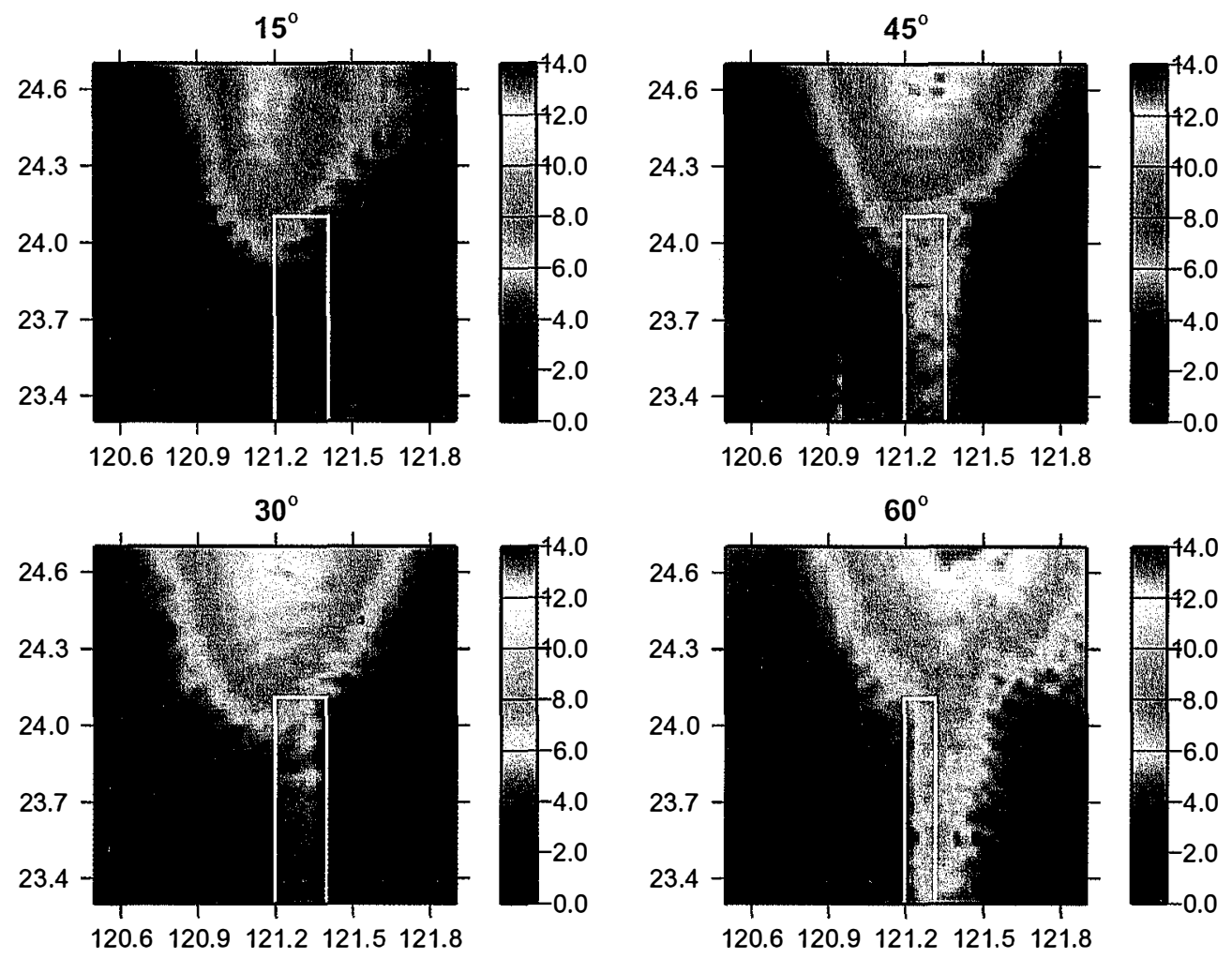

Fig. 3. Peak value snapshots of the simulate ground motion at different dip angles. The yellow rectangle shows the fault outline projected on the ground surface.

ground-motion snapshots for a fault rupture with different seismic velocity on the footwall side. The simulated results demonstrate that the ground-motion snapshots displayed the linear phase wave front when wave propagation velocity was lower then rupture velocity. The temporal evolution of those wave fields are clearly displayed in Fig. 4b.

\subsection{Influences of Rupture Velocity}

The rupture velocity is not uniform during fault fracture, and the rupture velocity of fault fracture from south to north decreases by degrees from 0.8 times $\mathrm{S}$ wave velocity to 0.6 times $\mathrm{S}$ wave velocity. The variation of rupture velocity of fault fracture from south to north is about 0.003 times $S$ wave velocity per kilometer. Figure 5 shows the ground-motion peak value with different dip angles. Comparing with Fig. 3, the directivity effect was estimated from the snapshots of ground-motion peak value and it was found that this effect becomes weak, no matter how low or high the dip angle is.

Figure 6 shows the simulated ground motion snapshots which are calculated with the 
(a)
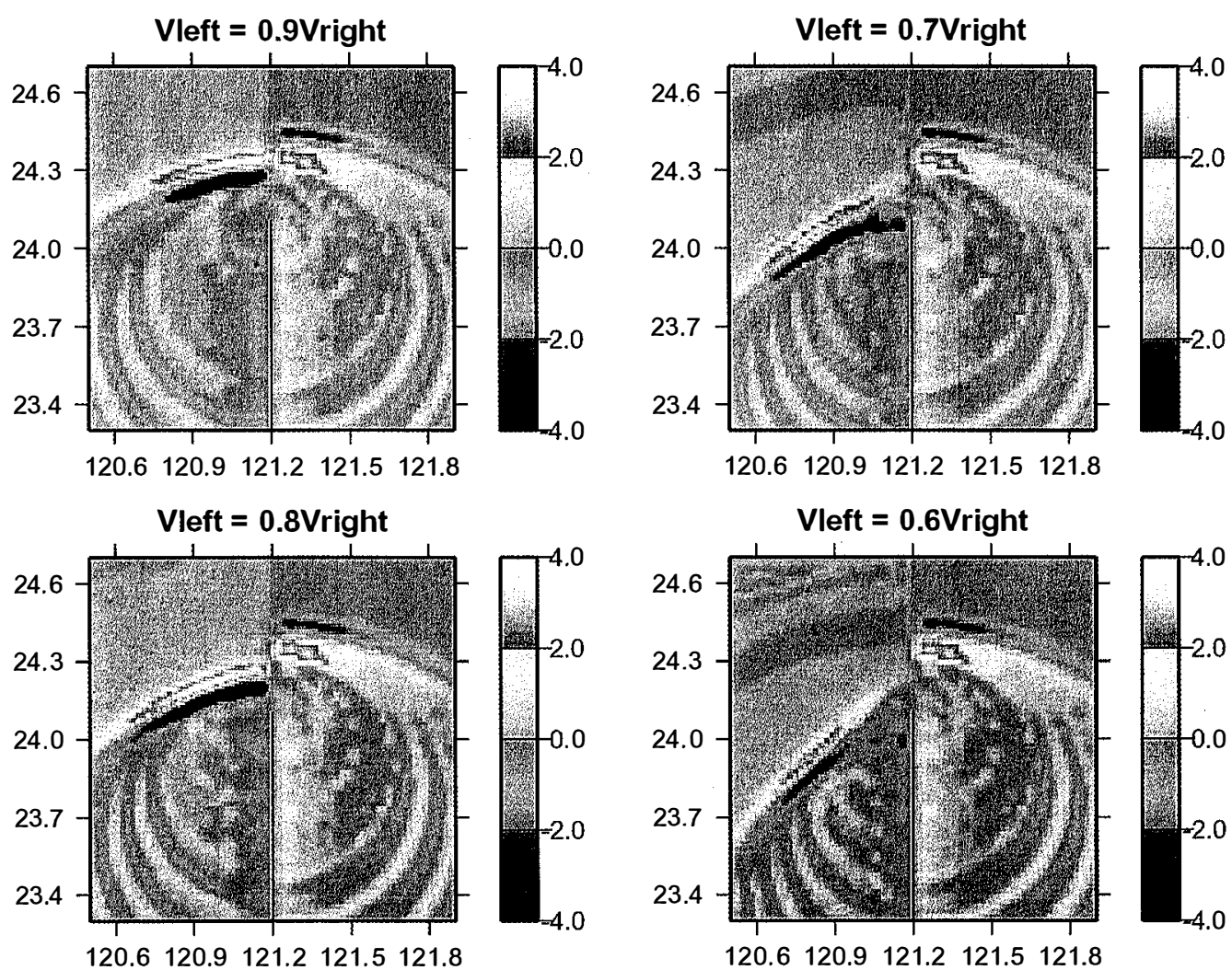

Fig. 4. (a) Line source ground motion snapshots with different seismic velocities on the hanging wall and the footwall. The red line shows the fault line projected on the ground surface. These snapshots depict the surface motion $40 \mathrm{sec}$ after the initiation of the rupture process. The snapshot, at the bottom left, assuming that the $S$ wave velocity on the footwall is 0.8 times the $S$ wave velocity of the hanging wall and the rupture velocity is equal to 0.8 times $S$ wave velocity on the hanging wall. The snapshots, on the right, have lower $S$ wave velocities on the footwall than its rupture velocity. The snapshot at the upper left has $S$ wave velocities on the footwall higher then its rupture velocities. (b) Ground motion snapshots of the plane source model in different seismic velocities on the hanging wall and the footwall. They are based on the assumptions that the $S$ wave velocity on the footwall is 0.6 times the $S$ wave velocity of the hanging wall, and the rupture velocity is equal to 0.8 times the $S$ wave velocity on the hanging wall. These snapshots depict the surface motion from $5 \mathrm{sec}$ to $40 \mathrm{sec}$ after the initiation of the rupture process. 
(b)
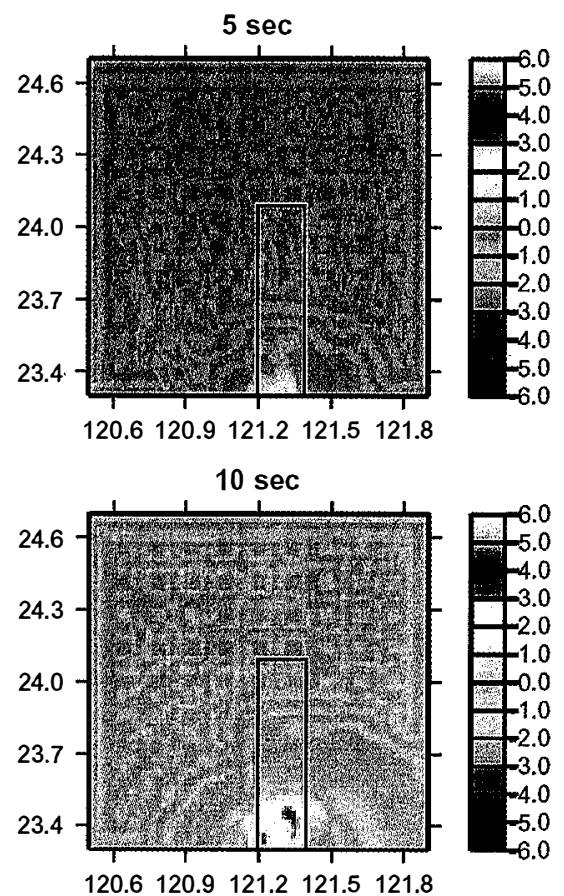

$15 \mathrm{sec}$
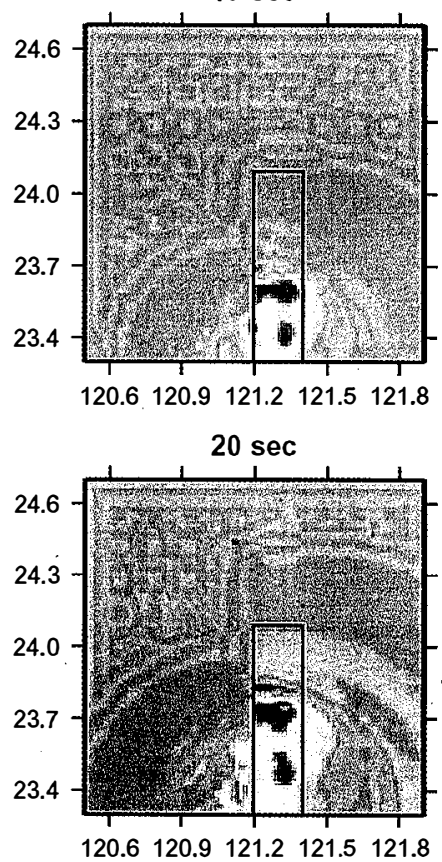
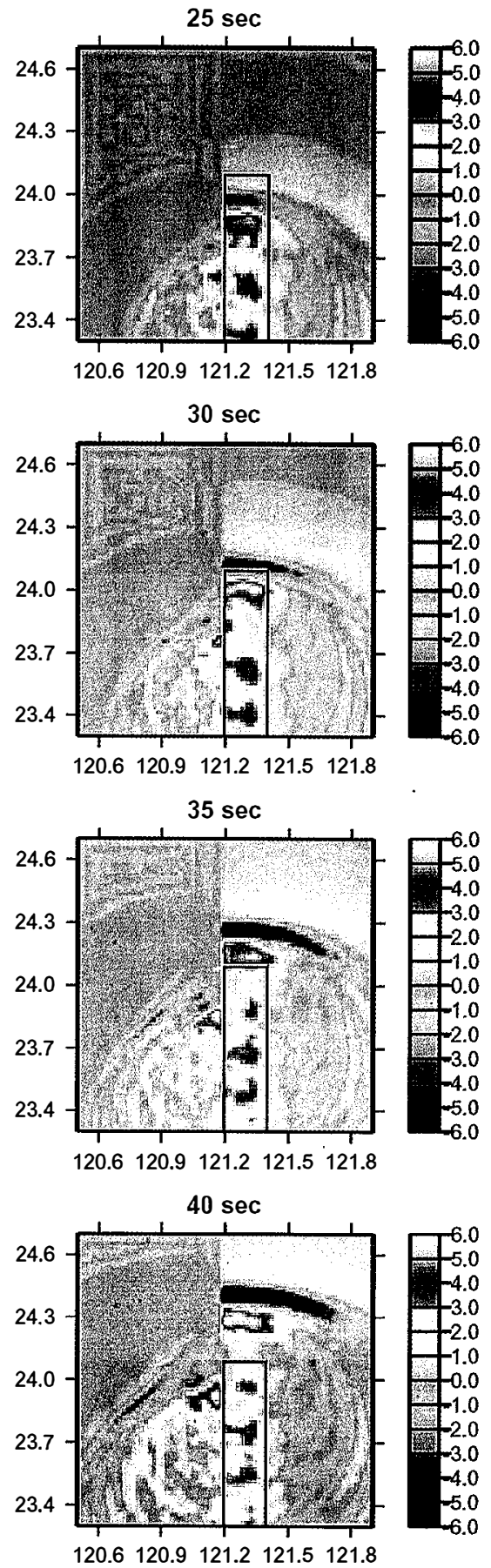

Fig. 4. (continued) 
same rupture velocity set as Fig. 5. The numbers in the parentheses are the difference of groundmotion peak value between the positions above the rupture start and the rupture end. Compared with the uniform rupture velocity case (Fig. 2), when the rupture velocity was lower than 0.8 times the $\mathrm{S}$ wave velocity, the difference of ground-motion peak value between the positions above the rupture start and the rupture end had decreased.

\section{DISCUSSION AND CONCLUSIONS}

At 1:47 a.m. (local time) of 21 September 1999, an $M_{w}=7.6$ earthquake struck central Taiwan near the town of Chi-Chi. The source focal mechanism of the Chi-Chi earthquake was a pure reverse type dipping 30 degrees to the east, at a shallow depth of less than $10 \mathrm{~km}$. It trigged an active fault (the Chelungpu fault), which was $90 \mathrm{~km}$ long, north-south trending, and
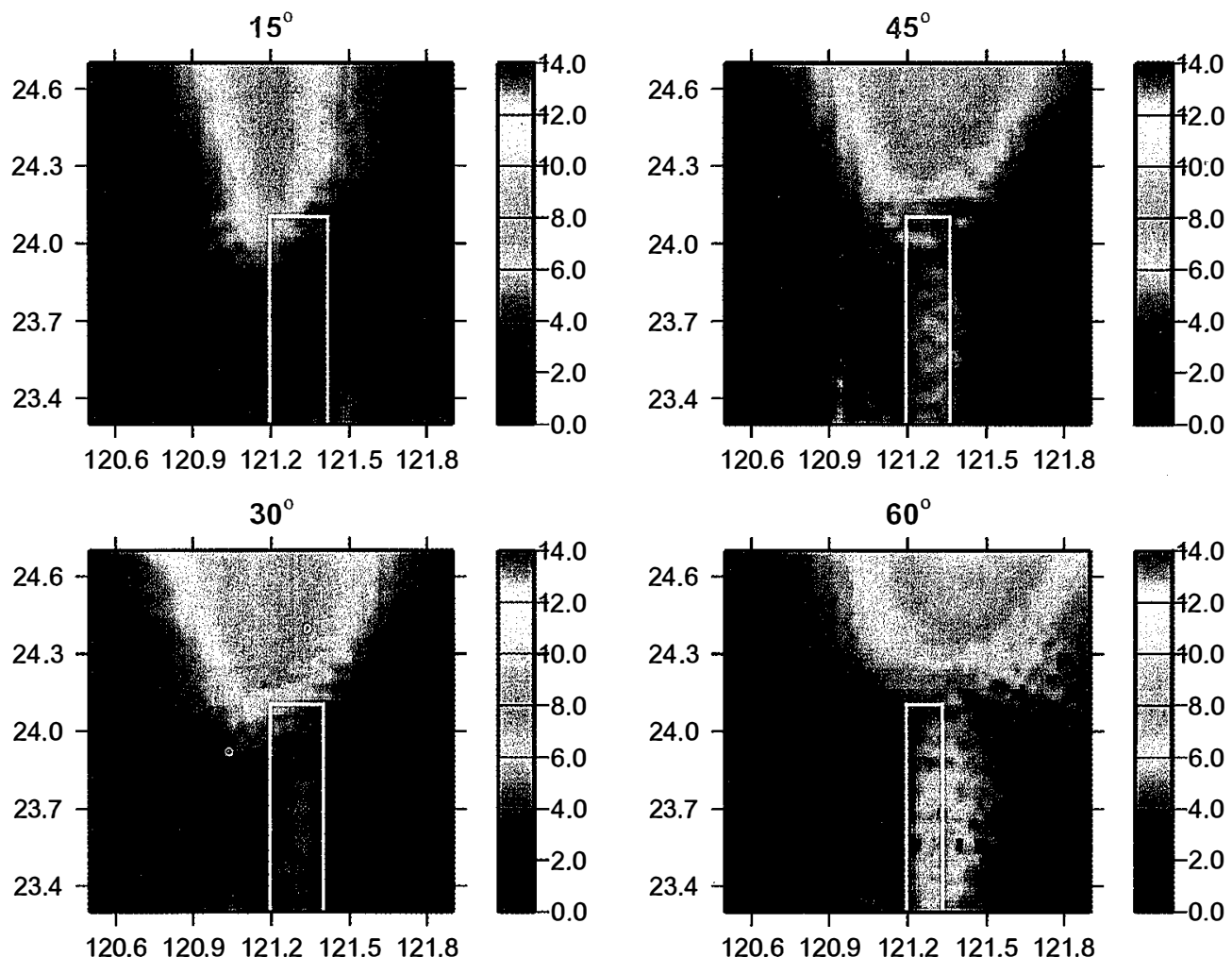

Fig. 5. Peak value snapshots of the simulated ground motion at different dip angles. The rupture velocity of fault fracture from south to north decreases from 0.8 times the $S$ wave velocity to 0.6 times the $S$ wave velocity. 

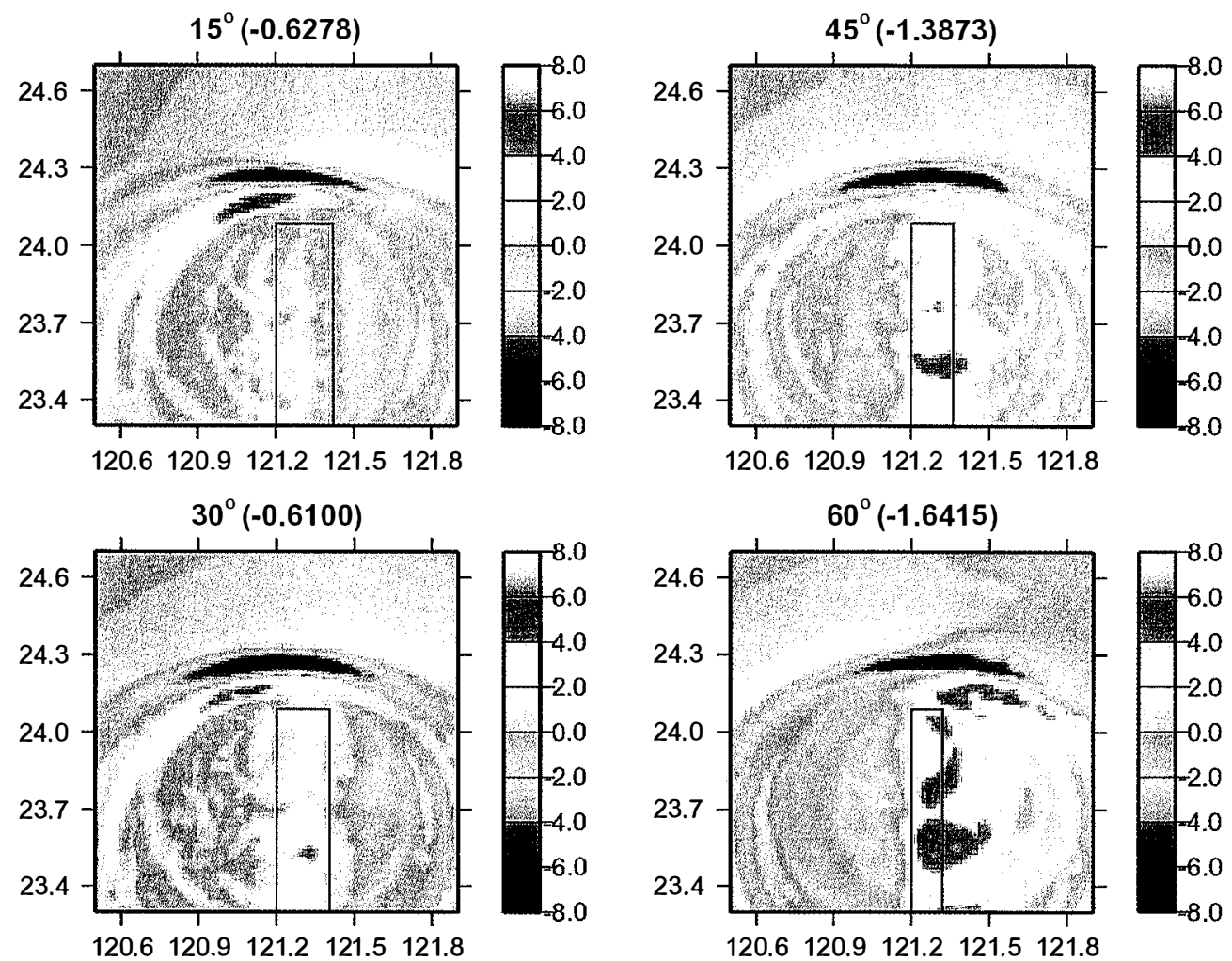

Fig. 6. Ground motion snapshots and the difference (the numbers in the parentheses) of ground motion peak value between the positions above the rupture start and the rupture end at different dip angles. These snapshots depict the surface motion $35 \mathrm{sec}$ after the initiation of the rupture process. The rupture velocity of fault fracture from south to north.decreases from 0.8 times the $S$ wave velocity to 0.6 times the $S$ wave velocity.

was mostly of the thrust type. The source rupture covers an area nearly $100 \mathrm{~km} \mathrm{x} 40 \mathrm{~km}$ in length and width, respectively. All the observations definitely indicated different responses of ground motion on the hanging wall side and on the footwall side. Results from source rupture inversion showed the fault ruptured from south to the north, and revealed the west movement of the hanging wall to the footwall on the eastern dipping angle (Kikuchi et al. 2000; Lee and Ma 2000; Ma et al. 2000). Figure 7 is the near source 2-D ground motion snapshots which were reconstructed from the observation records of Chi-Chi earthquake (Huang 2000). In this figure, the pattern of wave front propagation was very different between the western and eastern side of the earthquake fault. The source rupture propagated toward the northern end of the 

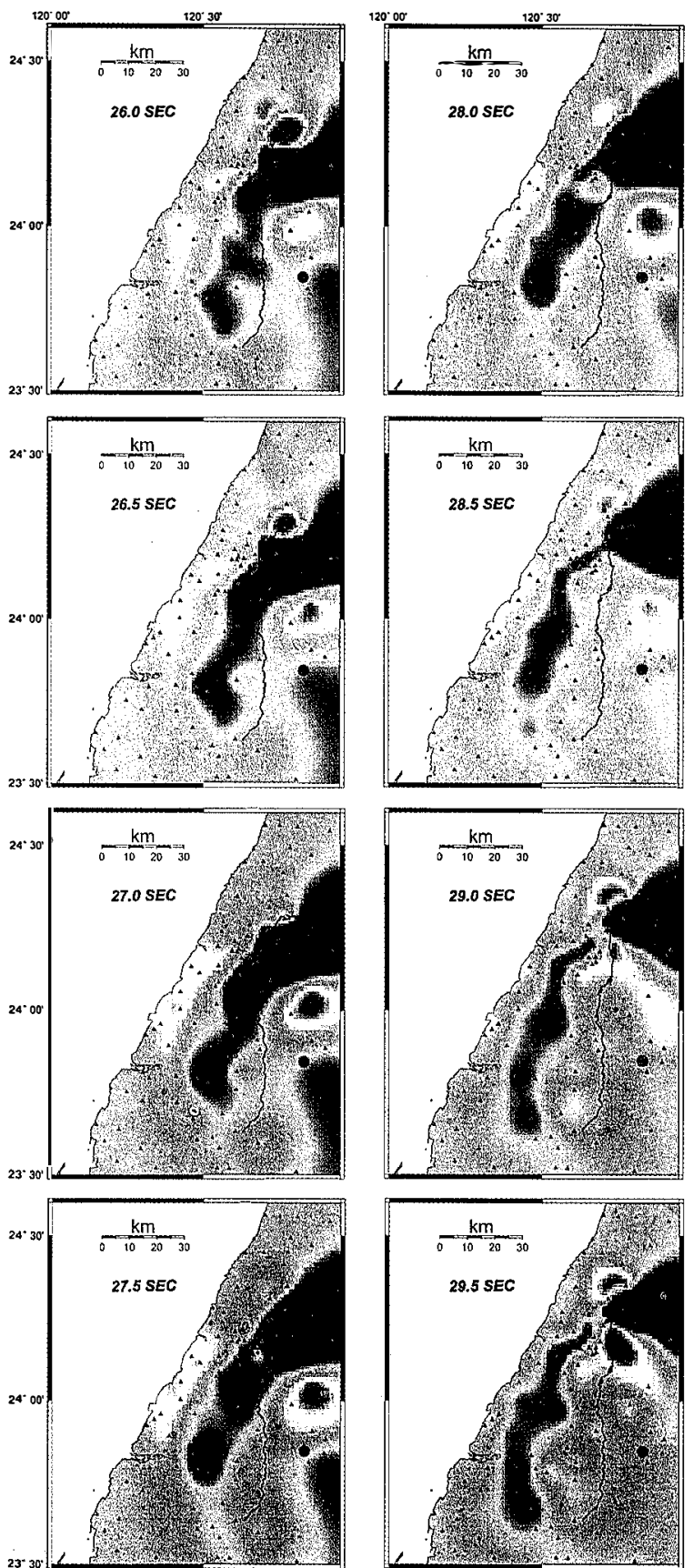

Fig. 7. Ground motion snapshots in the near-source area. The first snapshot, at the top left, is taken $26 \mathrm{sec}$ after the onset of the source rupture. The succeeding panels are taken $0.5 \mathrm{sec}$ apart. The last snapshot depicts the surface motion $29.5 \mathrm{sec}$ after the initiation of the rupture process. The colors and accomplished positive and negative numbers on the scale bar indicate the upward and downward ground motion of the wavefields (Huang 2000). 
fault and displayed the sharp linear phase wave front propagation from the fault plane in the northwest direction on the footwall. This phenomenon is similar to the modeling results of Fig. 4 and its reason may be due to lower seismic velocity than its rupture velocity in the foot wall side.

Based on the summary of the ground-motion snapshot characteristics that resulted from several assumed cases, we proved that the source shape, dip angle, uniform or non-uniform rupture velocity, and velocity structure could be very important factors influencing how a ground-motion wave field develops. Herein, comparing with the observation records, we support that: The Chelungpu fault had lower velocity structure in the footwall than in the hanging wall, and the seismic velocity on the foot wall side was lower than the rupture velocity of the Chi-Chi earthquake.

Acknowledgements The authors wish to express their appreciation to the Central Weather Bureau and the Institute of Earth Sciences, Academia Sinica for providing data used in this study. They also thank Prof. C. Y. Wang, K. F. Ma and K. B. Ou for their useful comments and valuable discussions. This study was supported by National Central University, Academia Sinica and the National Science Council, R.O.C., under grants NSC90-2119-M-001-005 and NSC90-2116-M-001-011.

\section{REFERENCES}

Beroza, G. C., and P. Spudich, 1988: Linearized inversion for fault rupture behaviour: application to the 1984 Morgan Hill, California, earthquake. J. Geophys. Res., 93, 62756296.

Dalguer, L. A., K. Irikura, J. D. Riera, and H. C. Chiu, 2001: Fault dynamic rupture simulation of the hypocenter area of the thrust fault of the 1999 Chi-Chi (Taiwan) earthquake. Geophys. Res. Lett., 28, 1327-1330.

Hartzell, S. H., and T. H. Heaton, 1983: Inversion of strong ground motion and teleseismic waveform data for the fault rupture history of the 1979 Imperial Valley, California, earthquake. Bull. Seism. Soc. Am., 73, 1553-1583.

Huang, B. S., 2000: Two-dimensional reconstruction of the surface ground motions of an earthquake: the September 21, 1999, Chi-Chi, Taiwan Earthquake. Geophys. Res. Lett., 27, 3025-3028.

Huang, B. S., K. C. Chen, W. G. Huang, J. H. Wang, T. M. Chang, R. D. Huang, H. C. Chiu, and C. C. P. Tsai, 2000: Characteristics of strong motion across a thrust fault tip from the September 21, 1999, Chi-Chi, Taiwan Earthquake. Geophys. Res. Lett., 27, 27292732.

Johnson, L. R., 1974: Green's function for Lamb's Problem. Geophy. J. R. astr. Soc., 37, 99131.

Kikuchi, M., Y. Yagi, and Y. Yamanaka, 2000: Source process of the Chi-Chi, Taiwan earthquake of September 21, 1999 inferred from teleseismic body waves. Bull. Earthq. Res. Inst. Univ. Tokyo, 75, 1-13. 
Lee, S. J., and K. F. Ma, 2000: Rupture process of the 1999 Chi-Chi, Taiwan, earthquake from the inversion of teleseismic data. TAO, 11, 591-608.

Ma, K. F., T. R. A. Song, S. J. Lee, and H. I. Wu, 2000: Spatial slip distribution of the September 20, 1999, Chi-Chi, Taiwan, earthquake (Mw 7.6) - inverted from teleseismic data. Geophys. Res. Lett., 27, 3417-3420.

Oglesby, D. D., and S. M. Day, 2001: The effect of fault geometry on the 1999 Chi-Chi (Taiwan) earthquake. Geophys. Res. Lett., 28, 1831-1834.

Shin, T. C., 1993: Progress summary of the Taiwan strong motion instrumentation program. Symp. on the Taiwan strong motion instrumentation program, 1-10.

Shin, T. C., K. W. Kuo, W. H. K. Lee, T. L. Teng, and Y. B. Tsai, 2000: A preliminary report on the 1999 Chi-Chi (Taiwan) earthquake. Seism. Res. Lett., 71, 24-30.

Takeo, M., 1987: An inversion method to analyse the rupture processes of earthquakes using near-field seismograms. Bull. Seism. Soc. Am., 77, 490-513.

Wang, C. Y., C. H. Chang, and H. Y. Yen, 2000: An interpretation of the 1999 Chi-Chi earthquake in Taiwan based on the thin-skinned thrust model. TAO, 11, 609-630.

Wen, L., and D. V. Helmberger, 1997: Propagational corrections for basin structure: Landers earthquake. Bull. Seism. Soc. Am., 87, 782-787. 